\title{
Methodology to Facilitate Successful Lean Implementation
}

\author{
Tomaž Berlec ${ }^{1, *}$ - Mario Kleindienst ${ }^{2}$ - Christian Rabitsch² - Christian Ramsauer $^{2}$ \\ 1University of Ljubljana, Faculty of Mechanical Engineering, Slovenia \\ ${ }^{2}$ Graz University of Technology, Austria
}

The implementation of lean production in a company is a transformation of the whole company's culture. To achieve such a lean culture, the role and support of management are decisive. This paper introduces a newly defined model and methodology with an interview guide which helps to distinguish a supportive from a non-supportive management team when introducing lean production, and helps to decide if a step needs to be repeated, improved, or the next step can be initiated. The methodology is especially suitable for small and medium-sized enterprises (SME's), because of their lack of human resources, where this model was also tested.

Keywords: corporate culture, lean production, management learning, interview guide, critical success factors

Highlights

- A model and methodology which helps to distinguish the level of management support when introducing lean production was defined.

- After each finished step an interview needs to be done, based on which the next step by lean production implementation is decided.

- Beside the needed lean production knowledge, special attention is paid to management support.

- This model is developed and especially suitable for SME's because of their lack of human resources.

\section{O INTRODUCTION}

The basic principles and practices of the Toyota production system (TPS) have been discussed for decades. Sugimori et al. [1] published one of the first scientific papers on this topic.

The practice now known as lean production (LP) has been changing and developing from a simple set of practices to the complexity of an entire lean business system [2] and [3]. As a result, knowledge and understanding about the theory behind LP is also evolving in [2] and [4].

In this research paper [5] the authors identify four key main factors that are critical for the implementation of lean manufacturing within small and medium-sized enterprises (SMEs), which are: leadership and management, finance, skills and expertise, and the culture of the recipient organisation. These four factors are defined, but least had been improved on the field of management support.

Pay [6] stated that there are four major reasons companies fail to achieve benefits through lean implementation. The first is that senior management is not committed to and/or doesn't understand the real impact of 'lean.' The second reason is that senior management is unwilling to accept that cultural change is required for lean to be a success. The third reason is that the company lacks the right people in the right positions, and the last reason is that the company has chosen lean as their process improvement methodology when a different process improvement program - or none at all - would have been the better choice. Based on Pay [6] these four major reasons for failure needs to be avoided or detected soon enough to prevent damage and LP failure.

Papers [7] to [9] identified a lack of senior leadership focus and complacency as barriers to lean manufacturing implementation.

A methodology for implementing lean manufacturing strategies was proposed which is able to systematically identify manufacturing waste, select appropriate lean tools, identify relevant performance indicators, achieve significant performance improvement, and establish lean culture in the organisation [10]. A management commitment transformation plan and the formation of a lean team should be enough to initiate a lean culture. But initiation of a lean culture is not sufficient, management needs to consistently stay supportive and not only at the start of LP implementation. A lean team cannot implement LP if management support is not absolute. Detection of unsupportive management should be done soon enough.

The creation of a lean culture is one of the greatest challenges awaiting the prospective lean implementers, since a considerable degree of organisational learning skills are needed [11]. This is why the LP implementation progress should be measured, and all employees have to be educated regarding $L P$. 
Herzog and Tonchia [12] presented an instrument for measuring the degree of lean implementation in manufacturing, based on a survey within 72 SMEs in Slovenia. They divided lean into eight lean issues with 24 lean variables, on which a company should be focused by implementing lean.

In the research [13] organisational culture and lean practices were investigated in correlation to successful and unsuccessful lean implementation. The authors concluded that a successful lean plant has a higher institutional collectivism, future orientation, human orientation, use of small group problem-solving, development of supplier partnership, customer involvement, adoption of continuous improvement, and lower assertiveness in comparison with unsuccessful lean plant. The results also indicate, that in order to implement lean management successfully it is fundamental to go beyond lean management technicalities by adopting soft practices and nurturing the development of an appropriate organisational culture profile.

To overcome the human resource barriers in successful lean implementation, the authors [14] identified a connection between barriers and performance measures. A framework to overcome each barrier was suggested.

The book [15] gives managers and executives the means how to maximise employee potential by increasing the improvement power. It also defines the people-related approaches and practices needed to alter any cultural dynamic. The authors stated, that everyone needs to learn and improve, and has to be involved. They suggest a five-year plan to make a long-lasting change requiring evolution of organisation, culture, and behavior.

In the research [16] the authors stated, that selecting the right person for the adoption of lean manufacturing in an industry will reduce the ambiguity, time consumption, and computation time. They proposed based on the TOPSIS-Simos method to identify a lean resourced employee in the industry.

A literature review on lean implementation and organisational transformation was done by [17], where the authors came to the conclusion that lean implementation is a transformational process, requiring organisational level support and changes. They also noticed that challenges and issues of lean implementation signify a lack of understanding of the organisational culture necessary for lean transformation.

Lean success factors were identified in the doctoral thesis of Pearce [18], including the extent of a business manager's own knowledge, which impacts the success or failure of an LP implementation. It turned out, that the main problems are the manager's knowledge and support for LP implementation.

Based on Pentlicki [19], who developed a deeper understanding of the barriers faced by SMEs and the strategies required for the successful implementation of lean manufacturing, senior leaders have varying definitions of their roles in leading lean manufacturing implementation [20], have differing perspectives regarding the degree of leadership knowledge required for successful lean manufacturing implementation. They also struggle to expand lean manufacturing implementation into support departments such as engineering, purchasing, administrative functions, and sales. This means that all employees need to learn about lean, regardless of where in the company they work. However, the learning process needs to be different for management than for all other employees, which is taken into account in our new model.

In the paper [21] the authors propose a motivational lean game to successfully overcome the communication and motivation problems between management and other employees.

The paper [22] offers managers a better understanding of the relationship and impact that some of the most essential lean methods have on the performance of their operations, based on which managers will be able to take better and more effective decisions about the implementation of lean methods.

Kull et al. [23] stated that the successful use of lean manufacturing practices requires more than the use of tools. It depends on a nation's culture, as well as the company culture. The culture in a company depends on an example of the management, and a culture change is a long process which can be made by LP with management support.

A manager's role has changed radically with the implementation of LP [24]. The focus on managerial tasks has changed from managing processes to developing and coaching people. Hence the manager's role is to give clear direction for change situations [25].

Mostafa et al. [26] stated that by LP implementation the focus should be on human and technical factors in a parallel manner all times. The expert team building, lean monitoring, and controlling should also be included in the LP implementation.

Drew et al. [27] are convinced that by implementing a sustainable operational improvement, three aspects need to be taken into account: the operating system, the management infrastructure, and the mind-sets and behaviors of the staff. In our 
proposed model we tried to integrate all these three aspects.

A number of studies have been conducted to understand or identify the factors that affect the process of implementing LP. Among the factors that influence LP implementation, $55 \%$ of the studies mention the importance of management support and/or commitment. However, none of them clearly describes criteria to distinguish a supportive from a non-supportive management team. Marodin and Saurin [28], listed main factors that affect LP implementation. The most important are:

- managerial support and commitment,

- the ability, experience, and knowledge to conduct the lean implementation process,

- an organisational culture receptive to changes.

According to Anvari et al.'s [29] ranking of the most critical success factors (CSFs) in order of importance are management and leadership, and followed by organisational culture. From this we can conclude, that the main focus has to be on management and leadership.

Scherrer-Rathje et al. [30] mention the following CSFs: management commitment, management support, lean team autonomy, an employee's autonomy to make process improvements, information transparency, and an employee's early as possible involvement in lean.

According to [30], a lean project should also be introduced from the top down, because the bottom-up case requires too many resources. Besides that, open discussion with employees is very important, because if management leaves them in the dark, they do not know the lean goal they are expected to achieve. They need to see the whole picture of lean, and not only their work, because they can then position their work in the whole lean picture. They also proved that it is very important to implement lean on a small unit first (pilot project), where success is guaranteed, and then implement it slowly over the whole company. If the pilot project is a failure, lean implementation in the eyes of the employees is over.

Motivated by the failure rate of lean implementation in SMEs in Vietnam, the authors [31] proposed a new application model of lean management by recognising the role of human resources development in the lean implementation steps.

In the research [32] an empirical evidence for the important role of management support and communication by lean implementation was provided.
Based on the literature review, we can conclude that management support is outstanding as the most critical success factor in the implementation of LP.

Considering the fact that the whole organisational culture has to change, and all employees need to go through the lean learning process and participate in the lean implementation, it is very important to have proper human resources especially in management and people leading LP implementation in the company.

These are the reasons why we decided to build a model to facilitate successful lean implementation and define the criteria to distinguish between supportive and non-supportive management teams.

\section{THE MODEL TO FACILITATE SUCCESSFUL LEAN IMPLEMENTATION}

LP implementation is a strategic activity within a given organisation supported by management, as well as by other employees, and which will succeed only through joint action.

According to Womack and Jones [3] five lean principles (specify value from the customers perspective, map the value stream, make the valuecreating process flow, implement pull system, strive for perfection as the goal) are known for lean implementation, which will be the fundamental basis of our model.

As stated, management support is crucial for LP implementation, which depends on lean culture.

Based on these assumptions, we propose a model that will clearly show the state of management support in the company early enough to prevent the failure of LP implementation.

In order to be able to commit to a LP implementation, managers and other employees need to obtain lean knowledge, which is obtained not only through teaching, but also with training, observation, and experience - all of which together can be described as lean learning.

There is a difference if the decision for lean implementation was decided by stockholders (owners) or by management supported by stockholders. If the decision or idea originates from management, then there is already the first positive impulse and the start of the lean implementation is much easier.

If the decision came from the stockholders in the form of a command, managers will not feel safe and managerial resistance should be expected.

The proposed model for the methodology to facilitate successful lean implementation in SME's consists of five steps combined with lean learning for 


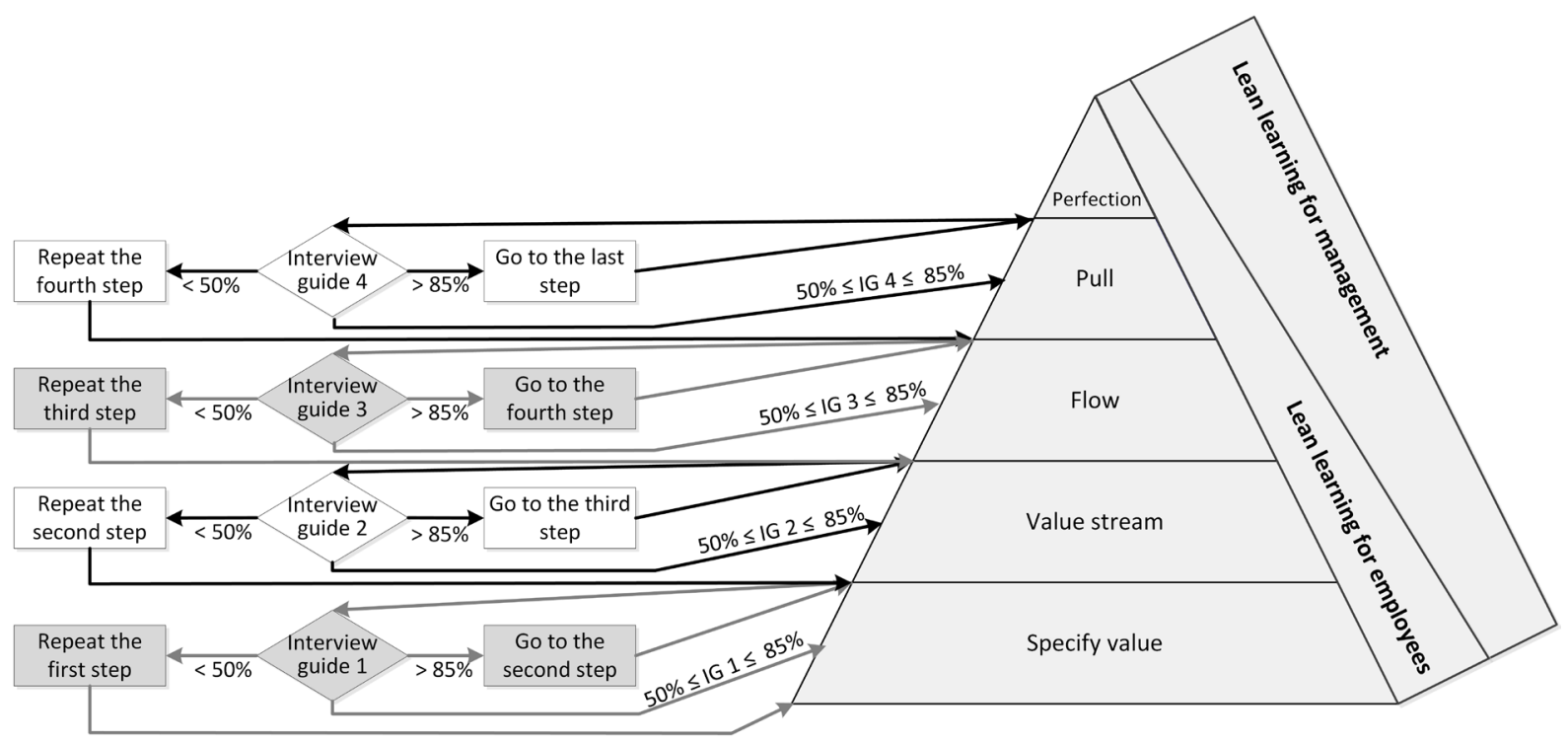

Fig. 1. The model to facilitate successful lean implementation

management and employees, which is shown in Fig. 1.

As seen in Fig. 1, all employees (at the managerial and operational levels) need to go through a lean learning process. In the beginning, all employees need to learn a lot of LP where the employees on the operational level are the focus for LP usage, and also on the managerial level on the usage with a focus on mentoring and encouraging operational employees. So besides the normal workshops, managerial employees need to have additional learning workshops.

In each step all the employees should grow in terms of LP knowledge based on workshops and practical deployment in their environment. This is why we make an interview after each step to check the practical knowledge, to see the management support, to avoid problems, and to resolve outstanding problems. The basis of a lean implementation is the step where the value is specified from the customer point of view. After completing this first step, the company needs to check the main points with employees using a proposed interview guide (IG).

\subsection{Interview Guide 1 - Specify Value (IG 1)}

1. What is the basic idea of lean philosophy?

2. Why is lean production useful to our company?

3. What are our customers willing to pay for?

4. What is your specific value-added?
5. Is the communication between employees and management satisfactory and the management support sufficient to implement LP?

The purpose of this first IG is to check whether all employees understand the basic principles of LP and the relationship of LP to the overall success of the company. By asking basic questions that every employee has to answer in his/her personal context, we enable individual answers - this is necessary because the great range of employee tasks in a manufacturing organisation make uniform answers difficult. The learning objective here is that the individual contribution to the overall system can be identified and valued by every employee.

Based on IG, we additionally want to facilitate successful lean implementation besides the general goal - a lean culture, which is the basis for perfection.

We recommend fulfilling the IG in the form of qualitative interviews, which are performed separately with managerial and operational levels. Besides that, each interviewee needs to give an assessment from $0 \%$ to $100 \%$ (Table 1 ) of his knowledge and his understanding after completing each step. This assessment needs to be consistent with the score given by interviewer. After finishing all the interviews the average assessment is calculated.

The interview scale is proposed based on proportional and cardinal scale [33] and grade scale used for knowledge evaluation process at the faculty. The interviewer gives an objective grade based on his knowledge and experience. 
Table 1. Interview scale

\begin{tabular}{ll}
\hline Percentage & Description \\
\hline $1 \%$ to $50 \%$ & Ignorance of the principles of lean \\
\hline $50 \%$ to $60 \%$ & High lack of knowledge, large uncertainties \\
\hline $60 \%$ to $70 \%$ & Lack of knowledge, less clarity \\
\hline $70 \%$ to $80 \%$ & A slight lack of knowledge, not sovereign \\
\hline $80 \%$ to $85 \%$ & A slight lack of knowledge, sovereign \\
\hline $85 \%$ to $90 \%$ & A slight shadow in knowledge, but still satisfactory \\
\hline $90 \%$ to $95 \%$ & The knowledge in its field reliable \\
\hline $95 \%$ to $100 \%$ & The knowledge is reliable on the whole company area \\
\hline
\end{tabular}

Table 1 shows the interview scale from $0 \%$ to $100 \%$, where percentages under $50 \%$ mean negative feedback, over $85 \%$ positive feedback and between $50 \%$ and $85 \%$ mean a shortage of lean knowledge or communication.

After a comparison of the results from both groups (managerial and operational levels), a decision can be made whether to proceed to the next step or not based on the proposed model (Fig. 1).

If the feedback from the IG is positive (over $85 \%)$ and the difference between the answers of managerial and operational levels is low, the step to the next level can be started.

If the feedback of the IG is negative (under $50 \%$ ) (lack of management support, low lean knowledge, bad communication, etc.), the same step needs to be repeated from the start.

In the case that the feedback is not negative and not positive (between $50 \%$ and $85 \%$ ), then the shortcomings have to be addressed first (with additional lean learning, with communication, etc.), and only then the next step can be initiated. In this case, the main thread is that the lean learning at all levels has to be repeated, where the loss of the valuable time cannot be avoided. This is why lean learning, the confirmation that all employees understand the lean philosophy, and know how to use it is very important from the beginning.

The same procedure with the IG described above should be followed after each step has been completed as shown in the model in order to facilitate successful lean implementation (Fig. 1). All questions in the IG are changed according to the additional step in the model, except one question remains the same in all IG through the whole LP implementation: "The communication between employees and management works well and management support is sufficient to implement LP," since management support is critical for LP implementation according our experience and the literature review in section 1 .
After step two has been completed the next Interview Guide can be started.

\subsection{Interview Guide 2 - Value Stream (IG 2)}

1. What is a value stream and the main idea behind it?

2. What are the value-adding activities and waste in general, and when thinking about your own workplace?

3. What does the current value creation process in your company look like?

4. What does your individual contribution to the whole value stream (supply chain, value add, preand post- process steps) look like?

5. Is the communication between employees and management satisfactory and the management support sufficient to implement LP?

The goal of the IG 2 is to check whether people understand the basic idea and their individual contribution to the value stream, and if they can distinguish between value adding and non-value adding activities in their own workplace and, of course, testing for management support.

Again interviewee needs to give an assessment from $0 \%$ to $100 \%$ consistent with the score given by interviewer. After finishing all the interviews the average assessment is calculated.

If the average assessment is between $50 \%$ and $85 \%$ that means, that not all employees understand the value stream principle, and a new learning cycle for value streams needs to be done before proceeding to the next step. If the average assessment is under $50 \%$, this step needs to be repeated.

Besides further theoretical explanation for employees and management combined with the practical input on their own workplace, management needs to think if they communicate the principles correctly and if the chosen training method is appropriate and meaningful for everybody. We suggest the use of lean learning factories as a proven method to train the key lean principles.

Learning factories represent a realistic company environment, for example an assembly area. Within this area, typical problems related to lean implementation and almost all relevant methods and tools within the lean philosophy can be elaborated. Within the neutral training environment of the learning factory, workers can experience the lean philosophy and its aftermath in practice. Furthermore, it is recommended to build interdisciplinary teams that do the training in the learning factory together. There should be people from all hierarchy levels and 
intra-organisational disciplines mixed up in order to create an exchange of ideas, problems, and thoughts that would help the organisation to improve lean implementation results. Such a learning factory has been in existence since early 2014 at the Institute of Industrial Management and Innovation Research at Graz University of Technology.

After all conditions from step 2 are met, that means that average assessment is over $85 \%$, step 3 - the flow can be carried out. When the third step is finished, the next IG (IG 3) is proposed.

\subsection{Interview Guide 3 - Flow (IG 3)}

1. I understand the necessary requirements to introduce flow.

2. I understand advantages of flow principle.

3. I can transfer theory to practice (flow in my area/ company).

4. I understand limitations of flow within my company and the relevant background.

5. I receive the right amount of information at the right time to successfully complete my tasks.

6. Is the communication between employees and management satisfactory and the management support sufficient to implement LP?

The idea behind IG 3 is to ask the basic questions that will clearly show whether the principles of flow production are understood from both the management level and operative level workers.

It is particularly important for operative level workers to understand the advantages of the flow principle. As very often the introduction of flow principles leads to repetitive tasks and workers tend to be less motivated performing these tasks, an awareness of the importance of this principle for the whole company is crucial.

The fourth question is aimed at the limitations of flow and the relevant background, and why flow is not always applicable. This question is intended to initiate thinking processes in all employees in order to help them come up with new innovative ideas on how to overcome these limitations. The fifth question aims to discover whether workers are provided with the right information. Since very important fragments of the flow principles are also the preparation and allocation of relevant information, this question is exceedingly important.

The procedure with assessment percent is the same as by the previous steps.

If the understanding of the managerial and operational levels on the flow principle is sufficient (average assessment over $85 \%$ ), and management support is satisfactory, the fourth step - pull can be initiated.

This does not mean that the flow principle has to work a hundred percent, in the meaning of KAIZEN it never will, but the fundamental basis should be introduced in the company environment.

After step four, the last IG is proposed.

\subsection{Interview Guide 4 - Pull (IG 4)}

1. I understand where the pull system helps to overcome the limitations of flow.

2. I still see potential for further pull implementation,

3. The lean culture is an important part of the company.

4. Is the communication between employees and management satisfactory and the management support sufficient to implement LP?

Pull production can be seen as a facilitator of the flow principle. Producing according to the demand of the next process step should help keep stocks low and prevent over-production. In this step, a lot of strategic considerations have to be kept in mind. This is why, in our point of view, extensive management involvement is indispensable in this step. Only the combination of strategic considerations from management level and operative improvement potentials from an operative level can lead to success and a move towards step number 5 .

It is very important that the transition to lean manufacturing and lean culture is made at all levels and in all areas of the company, and not only in production (as often seen), because only then can the lean culture in a company be developed.

Since lean implementation never ends because we strive for perfection, we can talk about the plando-check-act (PDCA) circle.

The proposed model to facilitate successful lean implementation is very suitable for SMEs, because of the shortage of people in SMEs for implementing LP. This helps them to keep a good overview over the LP implementation, and have quick and timely reactions if the LP implementation turns away from the optimal path. The use of this model also helps them to raise the rate of success of the LP implementation.

The same model can be also used in a big company to keep a good overview of LP implementation and to focus on the main problems by LP implementation.

\section{SIMULATION AND RESULTS}

The proposed model to facilitate successful lean implementation was tested in two SMEs. The first 
Table 2. An example of answers on IG 1 of one interviewee

\begin{tabular}{ll}
\hline Question & Answer \\
\hline What is the basic idea of lean philosophy? & $\begin{array}{l}\text { The basic idea is the elimination of waste in the company. } \\
\text { Maximise customer value while minimising waste. }\end{array}$ \\
\hline Why is lean production useful to our company? & $\begin{array}{l}\text { Things are getting more organised, Quality performance is better, we have fewer defects and } \\
\text { rework and lower levels of Inventory. }\end{array}$ \\
\hline What are our customers willing to pay for? & $\begin{array}{l}\text { Only for the added-value to the product. For example, for the final product, but not for the } \\
\text { transport and the rework. }\end{array}$ \\
\hline What is your specific value-added? & Injection molding of parts. \\
\hline $\begin{array}{l}\text { Is the communication between employees and } \\
\text { management satisfactory and the management }\end{array}$ & $\begin{array}{l}\text { Yes, the management supports the LP implementation. We have daily 10-minute morning } \\
\text { meetings to address and solve some problems. So the communication now is much better than } \\
\text { support sufficient to implement LP? }\end{array}$ \\
\hline before the start of LP implementation. \\
\hline Interviewee's assessment (from 0 \% to 100\%) & $95 \%$ \\
\hline
\end{tabular}

company, which we will call 'Company A,' has 90 employees and works in an automotive industry. They are specialised in the injection molding of multicomponent products, and in the complex injection molding of thin-walled products. They have just started the first step of lean implementation.

The second company, referred to as 'Company B,' has 208 employees, and is also working for an automotive, electrical, and mechanical industry. They work on special wiring harness with sensor technology, injection molded technical plastic products, and metallizing products. They expanded rapidly for the last seven years, and started the lean implementation a year ago, so we tried our model in the middle of an existing process of the lean implementation process.

First, the interdisciplinary lean core teams were built in both companies, based on [34], where the core team size depends on company size, theme, and project. The core team consists of six members in Company $\mathrm{A}$ and eight members in Company $\mathrm{B}$ which were acquainted with the model and the Interview Guides. After completing the first step in company A and the third step in company $\mathrm{B}$, the interviews were made. On average, five minutes were necessary for an interview because of the individual answers, for the interviewer to get an overview of the knowledge, and the consisting problems.

In Table 2, an example of IG 1, after Company A finished the first step is presented.

Based on the answers of employees, and the management, interviewee's, and interviewer assessment which were all over $90 \%$, we can conclude that the company is ready to go to the second step value stream.

In company B we also tried our model from the first step, although the company was already in the flow phase. However, they have some problems in implementing this phase. This is why we checked if they have any deficits in knowledge, and based on that, problems with LP implementation. So first we went over the IG 1, based on which we got an assessment by $95 \%$. Then we used the IG 2 , the company reached $80 \%$. After analysing the results, we can conclude that the employees have a lack of communication and knowledge about the value stream. That is why we made a weekend workshop on value streams. The same problems regarding communication and knowledge were solved in this workshop. After this workshop the company continued with the LP implementation, which went much more smoothly. After a month we repeated the IG 2 and they reached $95 \%$.

Based on these two different examples in different stages, we can conclude, that our model helps to facilitate successful lean implementation, because it shows the problems of managerial support, communication, and knowledge. These problems, when they are recognised, can be solved very fast and easily. But normally these problems are not recognized, and if the company waits too long, the problems increase and the LP implementation will be unsuccessful.

\section{CONCLUSION}

Based on the literature review and the lack of the timely detection of management support by LP implementation, a new model was proposed to facilitate successful lean implementation in SMEs. The model consists of five steps: specify value; value stream; flow; pull and perfection, combined with lean learning for management and employees and supported by four interview guides; and conducted after each step of the LP implementation plan with a 
strong emphasis on knowledge, management support and communication.

With the help of the proposed model, a company can monitor and simultaneously verify the LP implementation and can immediately react to a small sign of poor knowledge or lack of management support that is critical to the LP implementation, and which was tested in two different companies.

The IG are meant as a guide for interviews after each step defined by the model, based on which the company can easily conduct a review after each step, before the LP implementation deviates from the right path of successful LP implementation and growth of healthy lean culture.

Beside the needed knowledge, special attention is paid to management support with a question that is asked after each step, since management support can be quickly forgotten after dealing with new, possibly hidden production problems.

This proposed model accompanied by the IG is a 'simple guide' that needs to be followed by a company that is implementing LP.

With the help of the proposed model and the four IG, a company will have a much higher success rate than without them.

This model is developed and especially suitable for SMEs because of their lack of human resources. However, the model can also be used for a large scale industries, where they have a department for lean implementation or at least one employee for this task, but with the help of the proposed model, a company can monitor and simultaneously verify the LP implementation and can immediately react to a small sign of poor knowledge or a lack of management support that is critical to the LP implementation.

Our future research will continue with the proposed idea by upgrading the model for the implementation of agile manufacturing and agile manufacturing.

\section{REFERENCES}

[1] Sugimori, Y., Kusunoki, K., Cho, F., Uchikawa, S. (1977). Toyota Production System and Kanban System Materialisation of Just-in-time and Respect-for-human System. International Journal of Production Research, vol. 15, no. 6, p. 553-564, DOI:10.1080/00207547708943149.

[2] Hines, P., Holweg M., Rich N. (2004). Learning to Evolve. A Review of Contemporary Lean Thinking. International Journal of Operations \& Production Management, vol. 24, no. 10, p. 994-1011, D0l:10.1108/01443570410558049.

[3] Womack, J.P., Jones, D.T. (2003). Lean Thinking: Banish Waste and Create Wealth in Your Corporation, (2nd ed.), Free Press, New York.
[4] Papadopoulou, T.C., Özbayrak, M. (2005). Leanness: Experiences from the Journey to Date. Journal of Manufacturing Technology Management, vol. 16, no. 7, p. 784-807, DOI:10.1108/17410380510626196.

[5] Achanga, P., Shehab, E., Roy, R., Nelder, G. (2006). Critical Success Factors for Lean Implementation within SMEs. Journal of Manufacturing Technology Management, vol. 17, no. 4, p. 460-471, Dol:10.1108/17410380610662889.

[6] Pay, R. (2008). Everybody's Jumping on the Lean Bandwagon But Many Are Being Taken for a Ride, Industry Week, from http://www.industryweek.com/companies-amp-executives/ everybodys-jumping-lean-bandwagon-many-are-being-takenride, accessed on 2015-6-29.

[7] Atkinson, P. (2010). Lean is a Cultural Issue. Management Services, vol. 54, no. 2, p. 35-41.

[8] Pirraglia, A., Saloni, D., Van Dyk, H. (2009). Status of lean manufacturing implementation on secondary wood industries including residential, cabinet, millwork, and panel markets. Bio Resources, vol. 4, no. 4, p. 1341-1358.

[9] Turesky, E.F., Connell, P. (2010). Off the Rails: Understanding the Derailment of a Lean Manufacturing Initiative. Organisation Management Journal, vol. 7, no. 2, p. 110-132, DOl:10.1057/omj.2010.14.

[10] Karim, A., Arif-Us-Zaman, K. (2013). A methodology for effective implementation of lean strategies and its performance evaluation in manufacturing organizations. Business Process Management Journal, vol. 19, no. 1, p. 169-196, DOI:10.1057/omj.2010.14.

[11] Rymaszewska, A.D. (2014). The challenges of lean manufacturing implementation in SMEs. Benchmarking: An International Journal, vol. 21, no. 6, p. 987-1002, DOI:10.1108/BIJ-10-2012-0065.

[12] Herzog, V.N., Tonchia, S. (2014). An instrument for measuring the degree of lean implementation in manufacturing. Strojniški vestnik - Journal of Mechanical Engineering, vol. 60, no. 12, p. 797-803, DOl:10.5545/sv-jme.2014.1873.

[13] Bortolotti, T., Boscari, S., Danese, P. (2015). Successful lean implementation: organizational culture and soft lean practices. International Journal of Production Economics, vol. 160, p. 182-201, Dol:10.1016/j.jjpe.2014.10.013.

[14] Rane, A.B., Sunnapwar, V.K., Rane, S. (2016). Strategies to overcome the HR barriers in successful lean implementation. International Journal of Procurement Management, vol. 9, no. 2, p. 223-247, D0l:10.1504/IJPM.2016.075266.

[15] Jekiel, C.M. (2011). Lean Human Resources: Redesigning HR Processes for a Culture of Continuous Improvement. Productivity Press, New York.

[16] Balaji, K., Senthil Kumar, V.S. (2016). Evaluation and selection of lean resourced employee in the manufacturing industries using the TOPSIS-Simos method. Proceedings of the Institution of Mechanical Engineers, Part B, Journal of Engineering Manufacture, Dol:10.1177/0954405416635069.

[17] Yadav, O.P., Nepal, B.P., Rahaman, M.M., Lal, V. (2017). Lean implementation and organizational transformation: A literature review. Engineering Management Journal, vol. 29, no. 1, p. 2-16, Dol:10.1080/10429247.2016.1263914. 
[18] Pearce, A. (2014). Lean Thinking and the Factors Necessary for Its Success, PhD thesis, University of Canterbury, Christchurch.

[19] Pentlicki, J.H. (2014). Barriers and Success Strategies for Sustainable Lean Manufacturing Implementation: A Qualitative Case Study, PhD thesis, University of Phoenix, Phoenix.

[20] Boyle, T.A., Scherrer-Rathje, M., Stuart, I. (2011). Learning to be Lean: The Influence of External Information Sources in Lean Improvements. Journal of Manufacturing Technology Management, vol. 22, no. 5, p. 587-603, DOl:10.1108/17410381111134455.

[21] Herakovic, N., Metlikovic, P., Debevec, M. (2014). Motivational lean game to support decision between push and pull production strategy. International Journal of Simulation Modelling, vol. 13, no. 4, p. 433-446, D0l:10.2507/ IJSIMM13(4)4.275.

[22] Belekoukias I., Garza-Reyes J.A., Kumar, V. (2014). The impact of lean methods and tools on the operational performance of manufacturing organisations. International Journal of Production Research, vol. 52, no. 18, p. 5346-5366, D0l:10.1 080/00207543.2014.903348.

[23] Kull, T.J., Yan, T., Liu, Z., Wacker, J.G. (2014). The moderation of lean manufacturing effectiveness by dimensions of national culture: Testing practice-culture congruence hypotheses. International Journal of Production Economics, vol. 153, p. 1-12, Dol:10.1080/00207543.2014.903348.

[24] Poksinska, B., Swartling, D., Drotz, E. (2013). The daily work of lean leaders - lessons from manufacturing and healthcare. Total Quality Management \& Business Excellence, vol. 24, no. 7-8, p. 886-898, DOI:10.1080/00207543.2014.903348.

[25] Heath, C., Heath, D. (2010). Switch: How to Change Things When Change is Hard, Crown Publishing, New York.

[26] Mostafa, S., Dumrak, J., Soltan, H. (2013). A framework for lean manufacturing implementation. Production \&
Manufacturing Research, vol. 1, no. 1, p. 44-64, Dol:10.1080 /00207543.2014.903348.

[27] Drew, J., McCallum, B., Roggenhofer, S. (2004). Journey to Lean: Making Operational Change Stick, Palgrave Macmillan, London, DOl:10.1057/9781403948410.

[28] Marodin. G.A., Saurin, T.A. (2013). Implementing lean production systems: Research areas and opportunities for future studies. International Journal of Production Research, vol. 51, no. 22, p. 6663-6680, Dol:10.1080/00207543.201 4.903348.

[29] Anvari, A.R., Norzima, Z., Rosnah, M.Y., Hojati, S.M.H., Ismail, Y. (2010). A comparative study on journey of lean manufacturing implementation. Asian International Journal of Science and Technology in Production and Manufacturing Engineering, vol. 3, no. 2, p. 77-85.

[30] Scherrer-Rathje, M., Boyle, T.A., Deflorin, P. (2009). Lean, take two! Reflections from the second attempt at lean implementation. Business Horizons, vol. 52, no. 1, p. 79-88, DOI:10.1016/j.bushor.2008.08.004.

[31] Nguyen, D.M. (2015). A new application model of lean management in small and medium-sized enterprises. International Journal of Simulation Modelling, vol. 14, no. 2, p. 289-298, D0I:10.2507/IJSIMM14(2)9.304.

[32] Worley, J.M., Doolen, T.L. (2006). The role of communication and management support in a lean manufacturing implementation. Management Decision, vol. 44, no. 2, p. 228-245, D0I:10.1108/00251740610650210.

[33] Götze, U., Northcott, D., Schuster, P. (2015). Investment Appraisal: Methods and Models. Springer-Verlag, Berlin Heidelberg, DOI:10.1007/978-3-662-45851-8.

[34] Rihar, L., Kušar, J., Gorenc, S., Starbek, M. (2012). Teamwork in the Simultaneous Product Realisation. Strojniški vestnik - Journal of Mechanical Engineering, vol. 58, no. 9, p. 534544, DOI:10.5545/sv-jme.2012.420. 